\title{
PERFIL VERTICAL E TEMPORAL DO VENTO NO CENTRO DE LANÇAMENTO DE ALCÂNTARA COM O USO DO MODELO WRF
}

\author{
Diogo Ramos ${ }^{1}, 4$, Adaiana Silva ${ }^{2}$, Paulo Iriart ${ }^{2}$, Gilberto Fisch $^{3}$ \\ ${ }^{1}$ Instituto Nacional de Pesquisas Espaciais, INPE \\ ${ }^{2}$ Instituto Tecnológico da Aeronáutica, ITA/DCTA, São José dos Campos \\ 3Instituto de Aeronáutica e Espaço, IAE/DCTA, São José dos Campos \\ ${ }^{4}$ diogonsramos@gmail.com
}

\section{INTRODUÇÃO}

No Centro de Lançamento de Alcântara - CLA (MA), diferentes tipos de foguetes são lançados com cargas úteis científicas (experimentos de microgravidade), sendo que a informação da meteorologia aeroespacial é muito importante. Portanto, é fundamental a investigação dos processos atmosféricos na microescala que envolvam a camada limite superficial. Com o contínuo progresso da modelagem atmosférica, pesquisas do vento têm sido aplicadas sobre a região do CLA (Silva, 2013).

Este trabalho tem como objetivo avaliar o modelo atmosférico WRF comparando-a com registros anemométricos entre os dias 20 a 24 de setembro/2008 no CLA.

\section{METODOLOGIA E RESULTADOS}

As medições da velocidade e direção do vento foram realizadas em uma torre anemométrica $\left(2,33^{\circ} \mathrm{S} ; 44,42^{\circ} \mathrm{W} ; 50 \mathrm{~m}\right)$ instalada no CLA nos níveis de $6,10,16,28,43$ e 70m de altura. Para comparação com o modelo WRF, usaram-se apenas os horários de 03, 09, 15 e 21 horas, períodos onde as previsões do WRF foram executadas. Os níveis verticais do WRF foram 10, 50 e 100m. As principais configurações das rodadas tiveram spin-up de 6 horas para rodadas de 72 horas, 3 domínios com resolução horizontal de 9, 3 e 1km (escolhido neste trabalho) e 42 níveis verticais. A lista das parametrizações físicas bem como outras configurações mais avançadas pode ser obtida em Silva (2013).

A Figura 1 traz a velocidade do vento durante os cinco dias avaliados. 


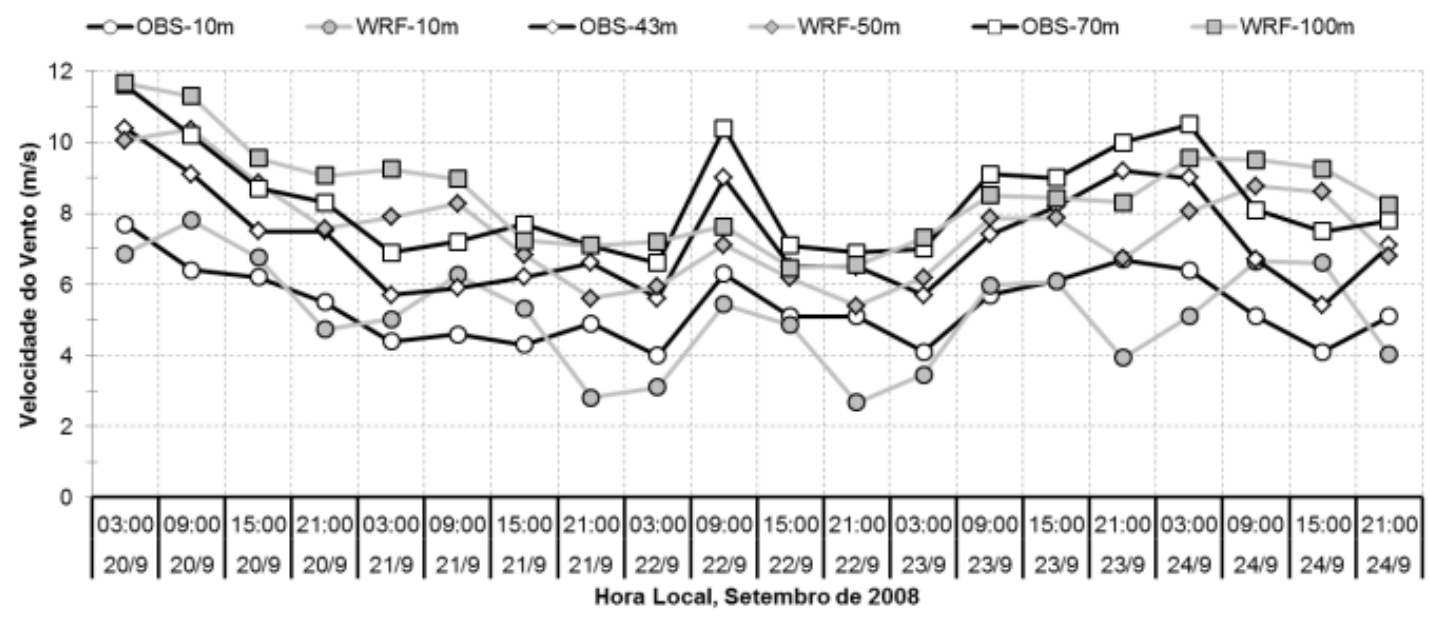

Figura 1. Velocidade do vento OBS e WRF entre 20 a 24/setembro.

Nota-se um comportamento inverso de magnitude do vento antes e depois deste período. Nos dias 20 e 21, as intensidades do vento, tanto OBS como WRF, decrescem no período entre 03 a $21 \mathrm{HL}$, enquanto nos dias 23 e 24, ocorre o contrário. Os desvios do vento entre noite e dia chegam a $2 \mathrm{~m} / \mathrm{s}$ em $10 \mathrm{~m}$ de altura, e até $3 \mathrm{~m} / \mathrm{s}$ nos níveis acima.

A Figura 2 traz os perfis verticais interpolados a partir dos dados OBS e WRF para o dia 24. Novamente, as superestimativas da velocidade no período diurno (até $2 \mathrm{~m} / \mathrm{s}$ ) e o contrário no noturno (até $3 \mathrm{~m} / \mathrm{s}$ ) são encontradas. A direção do vento OBS apresenta uma oscilação de até $15^{\circ}$ entre 10 e $40 \mathrm{~m}$ de altura neste dia, enquanto o perfil vertical WRF permanece quase constante, variando apenas temporalmente.
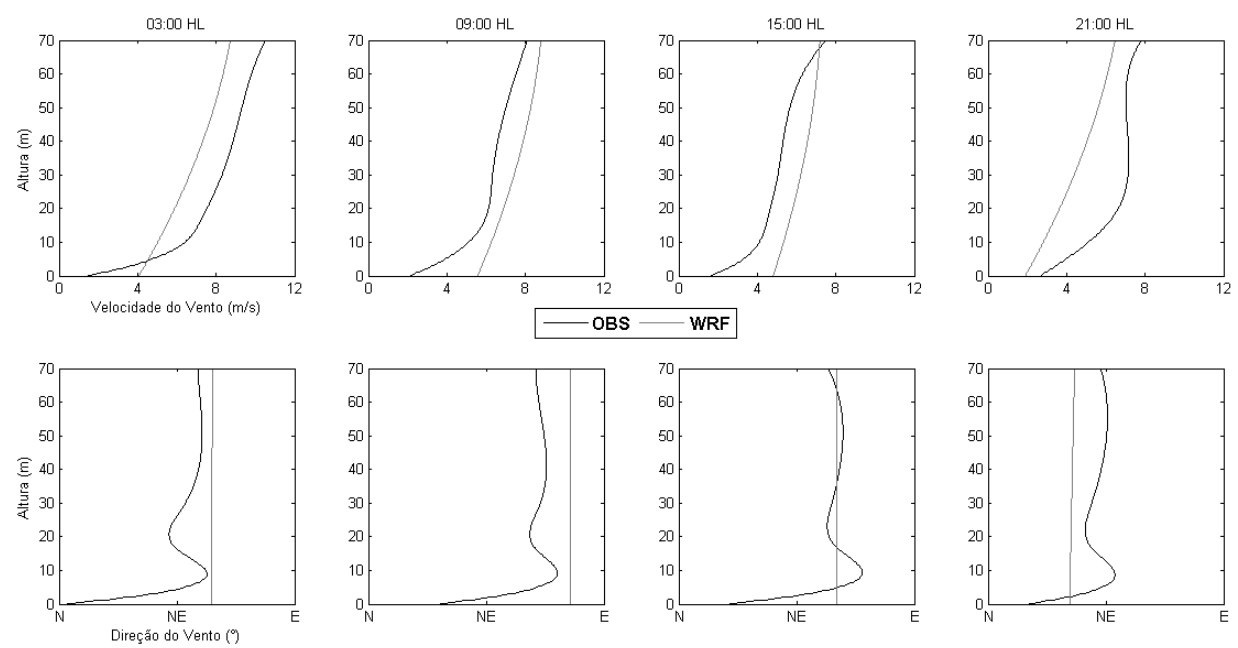

Figura 2. Perfil vertical da velocidade (linha superior) e direção (linha inferior) do vento OBS e WRF nos 4 horários do dia 24 de setembro de 2008. 
As mudanças diárias associadas à transição do regime de estabilidade dinâmica (noite) para a termodinâmica (dia) ocorrem no interior da camada limite planetária. Estas características ainda não são bem representadas nos modelos devido ao problema de fechamento dos parâmetros turbulentos dos campos envolvidos (Warner, 2011).

\section{CONCLUSÕES}

Este estudo apresentou algumas características importantes do vento através dos dados medidos e previstos pelo WRF. A velocidade do vento do WRF na escala temporal mostrou prognósticos superiores aos registros anemométricos durante o dia, e o inverso durante a noite. A direção prevista apresentou boa concordância com os dados observados, variando entre nordeste a leste durante o dia.

\section{REFERÊNCIAS}

SILVA, A. F. G. Avaliação do modelo WRF ao perfil do vento no Centro de Lançamento de Alcântara. Dissertação de mestrado em Meteorologia, Instituto Nacional de Pesquisas Espaciais, 100p. 2013.

WARNER, T. T. Numerical Weather and Climate Prediction. Cambridge University Press, 550p. 2011. 